\title{
RATIONALITY AND UNIVERSALITY: CONDITIONS AND ORDERLINESS \\ - ON \\ THE BORDER OF CONCEPT AND IDEA
}

Daniël F.M. Strauss

Department of Philosophy, University of the Orange Free State

ABSTRACT

Throughout the history of Western philosophy knowledge was closely related to universality and to conceptual knowledge - supposedly constituting the core meaning of rationality: rational knowing should be conceptual if it is to be recognized as knowing at all. Although Aristotle clearly realized that individuality is not conceptually knowable, he sidestepped this problem by introducing his secondary universal substantial form in order to safe-guard (conceptual) knowledge. A brief analysis of the further historical development of the relationship between universality and particularity paves the way for discussing the manner in which Dooyeweerd and Vollenhoven tackled this problem.

Vollenhoven's distinctions seem to be more fruitful, and are employed in order to get a better understanding of the nature of concept-formation - which always proceeds in terms of universality. But first of all an alternative approach to the distinction between concept and idea is explored by referring to the twofold way in which one can use modal terms: conceptually (pointing to phenomena evincing themselves within the modal boundaries of an aspect) and in an idea-context (using modal terms to designate states of affairs transcending the limits of the modal aspect in which the descriptive term has its original seat).

Against this background it is possible to give a more articulated meaning to the terms rationalism and irrationalism - the former restricts all knowledge to conceptual knowledge whereas the latter only acknowledges idea-knowledge of reality in its uniqueness, contingency and individuality. This classification entails the implication that we have to Koers $53(4) 1988$ 
use the terms individualism and universalism in the sense of atomism and (w)holism.

At this point our analysis proceeds by evaluating certain central traits in the thought of Dooyeweerd, Vollenhoven, Hart and Fowler. It is argued that particularly the latter two thinkers would benefit from using the mentioned distinction between concept and idea. In the case of Fowler it is also pointed out that his notion of God's "one and indivisible" will is still a demonstration of the after-effect of the rich Western legacy of a "simplicity-metaphysics" dating back, via Thomas Aquinas, Augustine and Plotinus, to Xenophanes. In connection with the influence of nominalism it is argued that Dooyeweerd indeed continued a central element of no-minalism by ignoring the universal side (orderliness) of entities.

As far as the distinction between individuality and typicality is concerned, reasons are advanced for using the term specify instead of individualize. This suggestion is closely connected with an alternative terminology for the dimension of entities in reality, framed differently by thinkers within reformational philosophy - such as individualitystructures (Dooyeweerd), identity-structures (Van Riessen), entitary structures (myself), and idionomy (Verbrugge). In following a verbal communication by Roy Clouser the notion of a type-law is also suggested.

In conclusion a succinct overview is given of the all-pervasive and directing influence exerted by modern nominalism on the philosophical development of the past five centuries - both in its rationalistic and irrationalistic variations.

\section{INTRODUCTION}

Contemporary philosophy of science indeed triggered off serious challenges to traditional theories of rationality. Since Popper relativized the uncritical nature of a positivistic "faith in reason" (Popper, 1945:231 $\mathrm{ff}$ ), the nature of scientific rationality has undergone a further scrutinization in the hands of Kuhn, Lakatos, Feyerabend, Stegmülier and others. However, within the whole legacy of Western epistemology $-614-$ 
one subtle assumption constantly surfaced: the supposition that conceptual knowledge constitutes the nature of rational knowing. A closer analysis of the multi-dimensionality of rationality, especially in connection with the nature of universality and the limits of conceptformation, is needed in order to gain more clarity about our ability to know. By doing this, our attention could not bypass traditional philosophical problems which directed in some or other way the main contours of Western philosophizing, such as the problem concerning universality and individuality. In passing, the problem of unity and multiplicity will also demand our attention.

\section{UNIVERSALITY AND PARTICULARITY}

The relationship between individuality and universality has confronted philosophy from its very beginning. " Plato was puzzled by the changing appearance of sensorially perceptible individual entities and took refuge to their supposed super-sensory (universal) 'essence' (eidos) to account for the underlying constant element which guarantees their knowability. Aristotle started from the pure individuality of his primary substance but had to transcend it to account for concept-formation in universal terms. The ideas of Plato were transformed into the creational ideas in the 'Divine Mind' during the middle ages, accompanied by Aristotle's (universal) secondary substance which was considered to represent the universal form of things having as a permanent substratum matter.

The realistic metaphysics of St. Thomas tried to synthesize the Aristotelian lex naturalis (with its dual teleological order) with certain fundamental biblical motives - ending with an idea partly inspired by St. Augustine which related the lex naturalis to a transcendent lex aeterna as the plan of creation in the divine Mind. The true beings of things are given as ideas in God's Mind. In a derivative and limited form individual things participate in the being of God - for every individual thing there is a corresponding idea in God (Questiones Disputate de

* A most illuminating and penetrating discussion of Aristotle's wrestling with this relationship was published by K. Zigterman (1981:18-53). 
Veritate, $(11: 8)$. Furthermore, Aquinas considered univer als (universalia) to have a threefold existence: universalia ante rem (the real existence of ideas before the creation in God's Mind); in re (in the things as their universal substantial forms) and post rem (their subjective existence in the human mind as universal concepts).

Emphasizing the primacy of the will (over against St. Thomas' choice for the primacy of the intellect), Ockham's nominalism only acknowledged the subjective existence of universals in the human mind (mens humana), encompassing both words (voces) and general concepts (conceptus) since every universal is a purely mental quality, no universal can really exist outside the mind (Summa Logicae, 1:14). Nothing but individual things exist in reality. Science, however, is still concerned with universals but then only as the subjective universal image of the real individual entities. Consequently, nominalism shifted the criterion of truth (for realism given in the adequatio intellectus et res) to the inner activity of the human mind - truth concerns the compatibility of concepts.

2.1 Universality and individuality in the Reformational Philosophy of Vollenhoven and Dooyeweerd

Vollenhoven acknowledged this relationship as a fundamental and legitimate philosophical problem, and developed the systematic view that universality is always accompanied by individuality and vice versa. He distinguished between three fundamental determinations of reality, namely the determination ("bepaaldheid') of model functions ("zus en zo"), the determination of "this and that" and the determination of good and evil. He called the difference between 'zus' and 'zo' (such and such) modal, and designated the difference between $a$ 'this' and a 'that' individual. In the history of philosophy Vollenhoven detected three possible positions concerning the relationship between the universal and the individual: universalism, partial universalism and individualism (cf. Vollenhoven, 1961:3). However, the descent of the terms 'universality' and 'individuality' are not accounted for by Vollenhoven.

The same applies to Dooyeweerd. He also frequently used the terms individuality and universality. What Vollenhoven called the "this and that"-determination is designated by Dooyeweerd as "structures of $-616-$ 
individuality". The way in which the law of God holds for creaturely subjects is often explained by using the expression "universal validity" (Dooyeweerd, 1953:151 ff). But nowhere in his works one will find any systematic analysis of the peculiar way in which these terms are used and whether they stem from either the dimension of "structures of individuality" or from the dimension of modal aspects.

In spite of this shared lack of explanation, there are also differences present in Dooyeweerd's and Vollenhoven's appreciation of the relationship between universality and individuality.

\subsection{Some differences between Dooyeweerd and Vollenhoven}

Dooyeweerd distinguished between the universality of God's law and the individuality of entities subjected to this (universally valid) law. Individuality is therefore, according to him, a feature of factual reality. Vollenhoven, on the other hand, distinguished between the universality of God's law and the universal law-conformity of subjects which are correlated with God's law (Vollenhoven:11). Dooyeweerd used the terms 'law' and 'law-conformity' ('wet' and 'wetmatigheid') interchangeably.

1 think Vollenhoven's distinction helps us better in understanding the relationship between universality and individuality on the one hand, and that between God's law and what is subjected to it on the other hand. Every entitary subject shows its being subjected to the universality of God's law in a universal way simply by being such and such. Being human, for instance, means nothing less than evincing certain universal features which are generally present in every particular human person. These features are factual features which must be distinguished from the law to which they conform. Conforming to a law is therefore a universal feature of subjects. (Compare the literal meaning of the Dutch term: 'wet-matig' = following the 'measure' of the 'law'.) Every particular person is not totally characterized by his factual individuality since his being a human person is part and parcel of his factual creaturely existence. Lingually this state of affairs is reflected in the respective use of the articles ' $a$ ' and 'the'. 'This' man/woman is ' $a$ ' human being; 'this' chair is 'a' chair; etc. 
Nevertheless, this perspective still does not give an account of the peculiar mode in which the terms universality and individuality are used. A possible alternative approach may be pursued along the following lines.

\subsection{A crucial distinction: concept and idea}

In the 'Festschrift' for Van Riessen (Strauss, 1982:159-173) I have explored one of his favourite philosophical sayings in certain directions. One of the most fruitful avenues opened up by this investigation was given in the new account of the distinction between concept and idea (limiting concept). It turned out that modal terms ${ }^{\star}$ may be used in two distinct (though not separable) ways:

(i) Either to describe states of affairs displaying themselves within the limits (modal boundaries) of a specific aspect, or

(ii) they may be used to designate states of affairs which transcend the limits of the aspect in which the descriptive term has its original seat.

The first option provides us with a conceptual use of modal terms, whereas the second one underlies an idea-use of such terms. Let us consider a few examples:

* The expression 'modal terms' refers to those terms which stem from the dimension of modal aspects. In the special sciences these terms mostly surface in a functional context - such as set (arithmetic), neighbourhood (topology), constancy (kinematics), causality (physics), life (biology), and so on. Terms designating functional relationships must be distinguished from concepts of concrete entities, such as atoms, molecules, macro-molecules, macro-systems, plants, animals, and so on. Important facets of this distinction between entitary and function concepts are already discussed in Cassirer's work from the year 1910: Substanzbegriff und Funktionsbegriff (Berlin). 
(a) Modal concepts are always formulated in relation to universal features of the different modal aspects (for example the concept natural number, set, dimension, cause and effect, and so on). Suppose we are thinking about a specific chair. If we look at the way in which this chair functions within the universal numerical mode of reality, we may refer to its feature of having four legs. Our concept of all chairs in this category must include the numerical feature of having a certain number of legs. Besides this conceptual use of numerical terms, we may reverse our approach and try to say something about the entire concrete existence of this chair, still by using numerical terms only. In this case we may say that this chair is unique. Another idea-use of the meaning of number is given in the expression: "This individual (particular) chair". The individuality of this chair is not at all limited or restricted to its numerical modal function. On the contrary, when we speak about its individuality we are thinking about the total existence of this particular chair, displaying its individuality in all its facets. But at the same time we must uphold that our idea of its individuality cannot be formed without the foundational (constitutive) aid provided by the primitive meaning of number - only on the basis of our numerical intuition of a multiplicity of distinct entities are we able to speak about the distinctness, uniqueness and individuality of this chair. This idea of its uniqueness and individuality is nothing but a limiting and referring way in which the point of entry of the arithmetical aspect is used.

(b) An idea-use of the modal meaning of the spatial aspect (with its inherent meaning of continuity, i.e., connectedness, implying the notion of coherence as well as the original spatial whole-part relation), entitles us to form the idea of the typical totality character (wholeness) of this chair, which refers to the trans-modal meaning of being an individual entity. Surely, this usage is distinct from the conceptual undertaking in which we try to measure the spatial dimensions of this chair, for in the latter case we are not using spatial terms to refer to the concrete reality of the chair which transcends the limits of the spatial aspect. Here we are simply interested in the way in which the chair functions concretely within the limits of the spatial aspect.

$-619-$ 
(c) The modal meaning of continuation (uniform motion, persistence, constancy), revealing the irreducible nature of the kinematical aspect, serves as point of entry to our idea of the identity of this chair and must be distinguished from the concept of the relative movement of the chair.

(d) The original physical meaning of change is synonymous with the modal meaning of energy-effect which may be identified with the cause-effect relation (causality). An idea-usage of the meaning of change provides the counterpart of the idea concerning the identity of the chair - it is ever-changing. Once again this idea should be distinguished from the typical, universally comprehensible, function it has in the physical modality (for instance its being weak or strong or its having a certain mass).

If we extend these idea-usages of the meaning of the mentioned aspects to approach reality in its totality, we may (partly following Van Riessen) say that everything is unique, everything coheres with everything else, everything remains identical to itself, and everything changes. Ideastatements (limiting concepts) like these do not exclude each other, but imply and presuppose each other.

From our preceding analysis we are in the position to trace the modal descent of the terms individuality and universality. Without our intuition of the nuclear meaning of number we won't be able to understand the distinctness or individuality of any entity. As such this notion therefore represents an idea-use of the modal meaning of number which transcends the limits of this aspect in its reference to the uniqueness of entities. The term universality, on the other hand, is only accessible on the basis of our understanding of the irreducible meaning of the spatial mode, because it refers to the spatial notion of location - whatever is considered to be universal is supposed to apply everywhere, i.e. universally. Its use is determined by the spatial time-order of simultaneity (at once). However, it seems that we here use the term universality in a conceptual sense, at least if we stick to the original modal meaning of space (continuous extension). When we approach the meaning of 'every' - in the sense of "each one" or even "all places" - from the arithmetical mode, we cannot side-step the deepened numerical meaning of infinity, namely -620 . 
the idea of an infinity of instances present at once (the "at once infinite"

in distinction from the primitive numerical meaning of infinity: the "successive infinite") ${ }^{*}$ In this case we are using the number-idea of the "at once infinite" (traditionally known as the "actual infinite").

The irreducibility of individuality and universality is therefore intimately connected with the irreducibility of the aspects of number and space, because these two modes fundamentally condition our reflection on the universality and particularity of entities - although it does not imply that we can deduce the nature of individuality from any modal aspect.

\section{A NEW PERSPECTIVE ON RATIONALISM AND IRRATIONALISM}

Concept-formation is always bound up with the universal order for, and the universal orderliness of things. This implies, as we saw, that one cannot grasp the individual side of entities in a concept. ${ }^{* *}$ Aristotle took this restriction to imply that the individuality of things is beyond the grasp of knowledge. Contrary to this view, we must recognise the fact that everybody has knowledge of things in their individuality, i.e. has knowledge of the individual side of things, even though this kind of knowledge is not conceptual. Much rather it is of a limiting and approaching nature, referring to the individual side of entities in terms of universal features. But this is simply another way to specify what 'ideas-knowledge' is all about - an idea concentrates a conceptual diversity upon (or refers it to) that which transcends the limits of all concept-formation.

* In an uncompleted study on the Philosophy of the Infinite these distinctions are developed in confrontation with foundational research in mathematics.

** De Vleeschauwer still continues this legacy consistently by saying: "But knowledge about what is individual is simply impossible" (1952:213). 
The standard legacy on rationality and knowledge sticks to this restriction of (rational) knowledge to conceptual knowledge. We may define this approach as rationalistic. Rationalism elevates the universal (or universality) as the only source of knowledge. Irrationalism, on the other hand, always wants to pay tribute to the contingent uniqueness of the individual side of things or events which, as we saw, transcends the limits of concept-formation. Irrationalism leaves no room for real conceptual knowledge.

Although it is tempting to define this divergent appraisal of the relationship between the universal and the individual in terms of the opposition between universalism and individualism, the latter opposition may be reserved to indicate alternative basic denominators for the cosmic diversity of aspects and entities.

REMARK: Individualism and Universalism

Those theoretical total-views of reality which use the discrete nature of the aspect of number (or analogies of number in later aspects) to explain cosmic reality in this entirety are called individualistic. Everything is reduced to a discrete multiplicity of elements (sometimes thought of as being in interaction - cf. sociological individualism). Universalism, on the other hand, rejects this 'additive' approach by claiming that some kind of a whole precedes every individual which is simply a dependent part of the larger whole. This use of the spatial whole-part relation (or analogies of this relation in other aspects) has numerous possibilities. Mostly it is associated with an organic whole and its parts, although it is possible to think organicistically in an individualistic way (by emphasizing the discrete numerical analogy in the biotical aspect) - one may mention Spencer who, in spite of his organicism, advocated a more pronounced individualism instead of a more pronounced nationalism. In his Politics, Aristotle indeed gave one of the classical formulations of universalism: "The state is, clearly, by nature prior to the household or to the individual human being; for the whole must be prior to the part" (1253 a 19-20). Modern system theory, following the foundational work of Ludwig von Bertalanffy, consistently explored a universalistic $-622-$ 
approach to reality with its emphasis on systems (wholes) and sub-systems (parts).

\subsection{A provisional comparison between Dooyeweerd and Vollenhoven}

Vollenhoven used these terms to indicate an overestimation of individuality and universality, respectively. Dooyeweerd, on the other had, used the correlation of universality and individuality (identified by him with the relation between law and factuality) to characterize the difference between rationalism and irrationalism. His denial of universality at the factual side of reality (the orderliness of entities) caused an unnecessary restriction in his definition of rationalism and irrationalism. Rationalism, in our view, is founded on an absolutization of conceptual knowledge, and we have seen that concepts are formed in terms of universality. But then rationalism cannot any longer be defined as an absolutization of the law-side of reality, as Dooyeweerd did, because universality is also present at the factual side of reality. Furthermore, it is then also insufficient to define irrationalism as an absolutization of the factual side of reality. It seems more appropriate to say that whereas rationalism leaves no room for true idea knowledge, irrationalism leaves no room for genuine conceptual knowledge.*

Although we do want to follow Vollenhoven in his distinction between law (order for) and Law-conformity (orderliness of), we prefer (in terms of our newly proposed understanding of the distinction between concept and idea on the basis of the irreducibility of individuality and universality), to call an over-estimation of universality rationalistic and an overestimation of individuality irrationalistic.

* A comprehensive analysis of the distinction between rationalism and irrationalism, dealing with conceptions within the tradition of reformational philosophy and developing a confrontation with other philosophers, is found in Visagie, 1979:246 ff. His distinctions in this respect are in harmony with the approach advocated in this article. 
According to Henk Hart "rational knowing" is "our understanding of structures, our grasp of general patterns, our insight into laws, kinds and properties $(1983: 16)$. Clearly, this definition is restricted to conceptual knowledge, banning idea-knowledge from the sphere of rationality. Although his whole argument about the integrality of human knowing, transcending the limits of "rational knowing" (or, in terms of our approach: conceptual knowing), is directed against the dominance of rationalism in our Western culture and scientific endeavours, he himself, in this respect, is still a victim of that very rationalistic tradition!

It is a pity that Hart did not enrich his excellent ontology of universality (1984) by implementing the distinction between concept and idea explicitly. Of course he had no alternative but to use modal terms frequently in idea-contexts without realizing it as such. For example, one will find an idea-use of the biotic term development (p. 152), of coherence and unity ( $p, 243$ ), unity (p.244), of dimensions (p. 260), of historical terms ( $p .265$ ) and even explicit idea-statements bout God (p. 319). Consider this last example. Hart states: "God is the origin of order. Theoretical analysis of God would require God to be within those bounds. But God is never subject to an order, nor limited by an structure" (p. 319). What Hart is actually saying, by using terms with a spatial connotation (such as 'subject' and 'limited') negatively, is that a conceptual use of terms stemming from within the bounds of the order of the world will never be appropriate when dealing with God. It is a small step ahead to acknowledge that, nevertheless, it is imperative that such terms are to be used in a referring and approximating (idea-)sense if we want to speak rationally about God at all. But then his own implicit identification of knowledge with conceptual knowledge should be transcended. Elsewhere, when Hart says: "God trancends creation" ( $p$. 337), he also does not realize that the term 'transcend' is nothing but a spatial term used in an idea-context.

In respect of the nature of individuality Hart once again stumbled on the illuminating distinction not drawn by him. Already on page 32 he mentions that, according to Hempel, rational disciplines or sciences can $-624-$ 
give an account of their subject-matter only in terms of general concepts, since none have the ability to "'grasp the unique individuality' of things - not even history". On page 78 he says that a concept is our grasp of conditionality (in its universality). "Consequently, about all that we can understand about individuality is that we all know it (my emphasis, DFMS). We intuitively grasp it, though we do not have a concept of it". As was the case in his 1983 article, Hart here also implicitly identifies rational knowing with conceptional knowing, but at the same time leaves room for someone to 'know' something by intuitively grasping what cannot be known conceptually. The 'knowledge' implied in this "intuitive grasping" is nothing but what we have termed idea-knowledge!

\subsection{The universal side of entities in Hart's ontology}

Hart correctly claims that universality and individuality are traits, not entities (1984:19). To this he adds the statement that norms, conditions, laws and so on relate universally to all thing "that in turn relate individually to them" (p. 19). One here implicitly senses a denial of the universal side of concrete entities - a fear that is strengthened later on when we read: "Subjects meet conditions uniquely, even when it is the same condition they meet" (p. 73). He proceeds: "No two frogs are the same, even though all frogs are frogs. The responses of any two frogs to the conditional order or configuration which we might call 'being a frog', which determines the reality of any possible frog, are individual responses" ( $p$. 37). Clearly, "being a frog" may not be identified with the conditions for being a frog. Frogs are creaturely subjects, and "being a frog" is a feature of these creatures, not of the order for their existence. We have argued above that "being a frog" (or: being an atom) is nothing but the universal way in which a concrete entity shows its being subjected to the universal law-order holding for its existence. In other words, it is not sufficient to state that individuality is the "way in which subjective existence meets conditions" (Hart, 1984:72), since every concrete creature meets the conditions for its particular existence both in its uniqueness and typicality (compare section 5 below). 


\section{STUART FOWLER ON GOD'S LAW AND THE PERSISTENT REGULARITIES IN CREATION}

Fowler reacts critically to the triadic distinction present in the thought of Spykman. Taljaard, Hart and Wolters - the distinction between three kinds of 'realities': God, law and creation: "Without claiming that this is the whole story about our knowledge of creational laws, therefore, these writers appear to be agreed in claiming that science involves an 'uncovering', albeit incomplete and tentative, of the ordering laws of creation, by theoretical analysis of the ordered creation" (Fowler, 1987:8). Fowler is convinced that "the idea of creational laws revealed in our experience of creation lacks biblical support" for "Scripture clearly testifies that creation reveals the person of God, in his righteousness, power and divinity, as the person who orders creation and guides and instructs man as his covenant partner in all the affairs of human life" (p. 8). Consequently, he wants to deny that "a coherent theoretical account of the Creator-creation relation" can be given "in terms of ordering laws mediating between God anci creation and accessible to rational thought about human experience of creation" (pp. 8-9).

According to him it is unbiblical to assume that "there is a distance between God and creation that is bridged other than by the person of God himself" and that "given the right conditions for that thought, the law that orders reality is accessible to rational human thought" (p.9). Whoever tries to think about "a set of impersonal laws that can be grasped in conceptual categories" (p.9) is engaged in impersonalizing God's personal ordering Word for creation. Postulating an impersonal law-order "owes more to the pagan notion of world-order of the Greek intellectual heritage than to the Biblical witness, even though it is identified with the Word of God" (p.9). Fowler stresses that the confession that the world of human experience is the creation of God ordered by his Word as its law in no way requires the notion that this Word is a law-order consisting of rules and conditions that God has set between himself and creation as some kind of third category linking God and creation. "The Word of God that is the ordering law for creation is not an intelligible order of laws detachable from the active presence of God, but is the self-consistent, righteous will of God for his creation that is implemented $-626-$ 
by his personal activity in the creation. ... The idea of ordering laws distinct from God and his ordering activity undermines the immediacy of the God/creation relation that is so fundamental to the biblical revelation" $(p, 9)$.

4.1 The Word of God - the problem of unity and multiplicty

Repeatedly we are informed that the "Word of God that orders creation", is "the one, indivisible Word that cannot be broken up or analysed into discrete rules in the manner of the laws of nature we formulate in our science" (p.10). * Although Fowler fully acknowiedges the ordering Word of God as the "correlate of the order (Fowler here should have used the word 'orderliness' - DFMS) we experience in the ordered reality of creation" he also holds that "we have no access to the content of the ordering will of God": "I suggest, therefore, that we need to abandon as a vain imagination the idea, persistent in Western though from the time of ancient Greece, that human thought can gain access, in one way or another, to the fundamental structuring principles, or ordering laws, of the universe" (p.10).

It is striking that Fowler here himself speaks impersonally about "structuring principles, or ordering laws, of the universe"! Also noteworthy is the plural: principles, laws. If God's ordering Word (will) is "one and indivisible", then every plurality of laws seems to be excluded. Furthermore, if he is serious in his acceptance of the correlation between the "persistent regularities" (cf. p.11) we can only experience (and only have access to), and the ordering will of God, then it is difficult to uphold this mystical simplicity metaphysics: how can God's ordering law be "one and indivisible" while creaturely reality, corresponding to that will, is multifarious and diverse!? Fowler claims that what "we can know, and all we can know, of God's ordering will for creation is what we

* On this page we once more read about the "one indivisible ordering Word". On page 12 we similarly read: "Creation is ordered by the activity of the personal God fulfilling his one, indivisible will for creation". 
experience of ordered reality - ... - together with the normative goals for human life revealed through the Scriptures" (p.10). Are these "normative goals" to be seen as God's ordering will for human beings? If so, then, in this regard, God's 'revealed will' is no longer "one and indivisible" but differentiated and specified according to the varying contents of these "normative goals"! Later on he speaks about "normative criteria" and about "the structure of normativity" (p.12), prompting the question: Does the "structure of normativity" or "normative criteria" belong to God's will? We are also frequently informed that there are certain "empirical and logical criteria" (cf. p.10). What is their (ontic) status?

What Fowler evidently did not recognize, is the authentic Greek "simplicity metaphysics" present in his own affirmation of God's will as being "one and indivisible". From the eleatic school of Parmenides, with its emphasis on the (static) and indivisible oneness (unity) of being, Western philosophy constantly underwent the influence of this simplicity speculation in various ways. Especially in the doctrine about the nature of God, scholastic and reformational theology is fundamentally influenced by the Greek speculation about the unity and indivisibility of being and divinity. "Fowler goes a step further than this traditional theological doctrine about God: he pulls God's law for created reality into the "one and indivisible" 'nature' of God - though inconsistently, since (as we have mentioned) he often refers to the "laws of nature" (in the plural) in the sense of God's will for nature: "It is important to note that, on the account $I$ am giving here, laws of nature are to be distinguished from the observed regularities that evidence them. Laws of nature are not

* Visagie demonstrates this Greek legacy convincingly. He shows that the combination of divinity and oneness dates back to the 6th and 5th centuries B.C. where Xenophanes already used it. Via neoplatonism ( $c P$. the elevated position of the indivisible 'One' in Plotinus' thought) and Augustin (who applied what Plotinus said about the 'One' to God), dogmatic thinking constantly used this pre-occupation with unity (and simplicity) as opposed to multiplicity. (Cf. Visagie, 1980:1-13.) 
to be identified with systematic logical formulations of observed patterns of regulatory. They are law-like features of the order of nature, as an ordered reality, that are evidenced in observed regularities. It is these law-like features that scientific laws endeavour to represent in lawformulations" (p.11).

First of all we want to point out that the so-called "scientific laws" are based on the mentioned regularities, but (at least in non-nominalistic trends) aim at formulating whatever holds as order for the observed regularities. In other words, science do not aim at purely fictitious 'laws', but at ontic laws which hold for created reality. Furthermore, if the "laws of nature" (as part of God's will) are evidenced in "observed regularities", it remains difficult to explain why this evidence could not rationally be related to God's "order for" which is evidenced in them. Evidence is always referring and pointing towards something else. 1 can think of no biblical ground that would preclude rational access to God's law for whatever is subjected to that creational law and even evidincing. it.

\subsection{Lack of differentiation in the "Word of God"}

However, I think I can see why Fowler objects. It. is because he does not start from the distinction between Creator and creation, but from the triadic problem of God, creation and the creation-order as a bridge between God and creation. This problem stems from Vollenhoven who used to speak about the being of God, the being of God's law, and the being of creation. From our analysis of nominalism we can see that nominalism does not acknowledge the universality of ontic laws. But whereas traditional nominalism transposes this universal order for things into the human mind (i.e., in Kant's notion, discussed below, of our understanding as the universal law-giver of nature), Fowler transposes all creational laws into the "one and indivisible" will of God! If we take seriously the completion of creation (mentioned in Genesis $2: 1$ ), * the crucial questions are: is there a difference between creation and the

* Fowler is also ambiguous on this point. He sometimes speaks about $-629-$ 
upholding of creation? and: what belongs to creation? The first distinction needed here is that between God's creative act "in the beginning" in Christ (cf. Vol.1:16), and God's on-going care for and upholding of creation in Christ (Col.1:17). Christ, as God's Creative Word and Maintaining Word, must be distinguished from God's Law-Word (Creation-Order). The latter belongs to creation and should be distinguished from Christ through Whom all things were created and now still consists.

God's expressed will for creation belongs to creation, and creation in its totality - both with respect to its law-side and factual side - is constantly depending on the caring and upholding Word of God (Christ). It is of no use to claim that God's will belongs to God - because whatever is subjected to God's laws also belongs to God! One cannot argue that the laws to which creatures are subjected should be connected with God, because every creature equally is connected to God simply by its being created.

It is also noteworthy to mention the fact that Fowler completely ignores the dimension of modal universality. What he calls "persistent regularities" are only related to typical entities which function in a specified way in the different modal aspects of reality (compare our next section). The identification of the modal dimension as such, distinguishable from the dimension of entities, requires an appeal to God's order for creaturely subjects, because no single typical function of whatever entity within any modal aspect could be accounted for without acknowledging the underlying universal modal structure which as such makes all specified functions within it possible. Typical laws are found on the basis of observed regularities, whereas universal modalities are identified with the aid of modal abstraction. " The modal order-diversity

the ordered creation, implying something completed, and sometimes about God's ordering will, suggesting an on-going concern.

* Nowhere in his article we find a critical assessment of what we should consider to be the distinctive feature of scientific thinking. Without arguing it in any detail, I want to point out that this is only to be -630 - 
therefore has the status of law - it is one dimension of created reality as to its law-side. If Fowler wants to be consistent, he should first of all transpose also the dimension of modal universality into the "will of God" and then deny its diversity on the ground that God's ordering will for creation is "one and indivisible"! The central commandment of love does have an unspecified and integral meaning - but it belongs to created reality where it is specified according to modal and typical laws: the way in which we love God whole-heartedly analytically is by identifying and distinguishing correctly; the way in which we love God whole-heartily economically is by exercising our stewardship in a frugal fashion; the way in which we love God whole-heartily in communal relationships such as that of the state is by striving towards a just public legal order; etc.

The wisdom literature of the Old Testament does not have any problems in seeing God's expressed will for creation as belonging to creation - just compare Psalm 148, praising the constancy of God's decrees. (Fowler also mentioned this Psalm in passing, without engaging himself in analysing this facet - CP. P. 10.)

Fowler accused Hart, Wolters and others that they identify a Greek notion of a law-order with the Word of God - but it turned out that he attempted exactly the reverse; he identified God's Word with the law-side (order for) of creation - and by doing that, under the influence of the metaphysical Greek speculation about the oneness and indivisibility of being (projected onto God) had (inconsistently) to deny the inherent diversity in this law-order. When we acknowledge creation both with respect to its law-side and factual side, we do not need the notion (correctly rejected by Fowler) that some third 'being', the 'law-order' that should mediate between God and creation, because from the Bible it is quite clear that Christ mediates between God and creation - as 'creation-Mediator', as 'upholding-Mediator' and as 'redemptive Mediator'. This threefold mediating role of Christ as Word of God should, however,

found in modal abstraction. This feature does not exclude an analysis of entities in reality, because the modal aspects serve as points of entry to reality - and in science as modes of explanation (cf. Stafleu, 1987). 
constantly be distinguished from the law-side of created reality, i.e. from God's law-order in its various dimensions (modal, typical, temporal and centrally religious).

1 want to raise one last point in this connection. Fowler neither accounted for the nature of concept-formation, nor for the role of universality in this context. If we do accept with him that, for example, God's will for physical reality according to its kinematical aspect relates to the uniformity of physical movement, he must acknowledge the universality of God's (according to him: conceptually unknowable) "one and indivisible" will for creation, for if this will of God does not hold universally for all moving creaturely subjects, no regularity would be discernible in our experience of moving entities. However, to acknowledge this entails the knowability of God's will in respect of its universality! But if we cannot deny its universality, albeit God's personal decree for creaturely subjects, then we have the decisive condition available for all concept-formation, because concept-formation always proceeds from universal features. Consequentiy, in this line of thought we eventualiy embraces God's persorial care for creation conceptually contradicting the fact that God transcends creation with its different features (such as universality). The difference between concept and idea is here needed - but it pre-supposes the distinction between God's Creation-Word, Upholding-Word, Incarnate Word, Redemptive Word and Law-Word.

\subsection{Dooyeweerd and Nominalism}

We have referred to the fact that nominalism acknowledged universality only within the mind of the human subject (either as universal concepts or as universal words). Recalling the definition which we have given for rationalism and irrationalism, we may now ask the question: is nominalism rationalistic or irrationalistic? In respect of the typical structure of entities, nominalism does not accept any conditioning order (universal structures for), or any orderliness (universal structuredness of) such entities. Every entity is strictly individual, in terms of our mentioned distinction, we may say that nominalism surely represents an irrationalistic view in connection with the structure of entities, since every entity is completely stripped from its universal orderliness (law$-632-$ 
conformity) and conditioning order. This characteristic applies to both moderate nominalism, viz. conceptualism (Ockham, Locke, Leibniz, and others) and to extreme nominalism that rejects all general and abstract ideas and accepts only general names (Berkeley, Brentano and others).

This irrationalistic side of nominalism, however, does not exhaust the multifaceted nature of nominalism, because universals are fully acknowledged in the human mind, at least as general words in the case of Berkeley's and Brentano's extreme nominalism. This restriction of knowledge to universals is typical of rationalism in the sense defined by us. Therefore, it is possible to see nominalism as being simultaneously rationalistic in terms of the universals - concepts and words - in one's mind, and irrationalistic in terms of the strict individuality of entities. (Nominalism's appraisal of the supposedly non-universal nature of concrete entities is of course internally antinomic, for these entities display at least one universal feature: being individual!)

In this context we only want to emphasize that Dooyeweerd's lack of appreciating the universal side of concrete entities functioning at the factual side of reality simply continues an element of nominalism's irrationalistic view on the pure individuality of entities outside the human 'mind'. For this reason he still identified the concreteness of entities with their individuality - compare his frequently used saying that things function in a concretely individual way in the universal modal aspects.

\section{5. "MODAL INDIVIDUALITY/TYPICALITY" - STAFLEU AND DOOYEWEERD}

In order to proceed from his analysis of the modal aspects of reality to the structures of individuality, Dooyeweerd discussed "the problem of individuality within the modal cadre of the law-spheres" as a transitional theme (1955:414 ff). The key-idea in his discussion is that the modal meaning must be 'individualized' ( $423 \mathrm{ff}$ ). Although I can fully appreciate the examples of "modal individuality" given by him, I do think that the way in which he accounted for them is problematic. If it is true that universality and individuality are irreducible to each other (closely connected with the irreducibility of the numerical and spatial points of $-633-$ 
entry used to speak about universality and individuality), then it is in principle impossible to speak about an 'individualization' of the modal meaning of any aspect - for the latter is strictiy universal.

Stafleu, in following Dooyeweerd, made a distinction between typical laws and modal laws. The former apply only to a limited class of subjects, whereas the latter have a general character. To this he added the following explanation: "Our first distinction (law and subject) is frequently identified with the distinction of universals and individuals. However, this identification is inadequate and too crude, since the distinction of typical and modal laws also implies a universal-individual duality" (Stafleu, 1980:6).

The 'two-sided' nature of entities, displaying both an individual and a universal side, implies that the concreteness of any entity comes in a 'two-sided' way to expression within the "universal cadre" of the modal aspects. As such, every entity functions in a concrete individual and in a concrete universal way within the modal aspects. Dooyeweerd correctly stressed the fact that "not a single law-sphere may be considered as the exclusive origin of individuality" (1955:418). However, keeping in mind that the term concretely encompasses both the individual and the universal sides of an entity, we cannot any longer maintain the notion of modal individuality as it is used by Dooyeweerd. Viewed from the angle of the modal aspects, one therefore encounters various forms of individuality and orderliness within each modality. The typical structure of an entity specifies (but never individualizes) the universal modal structure of an aspect. It is preferable to speak in this context of modal specificity in stead of modal individuality. Thermodynamics, for example, ${ }^{\star}$ is a general and fundamental physical discipline, abstracting completely both from the individuality and the specificity of physical entities. It therefore uses modal function concepts such as volume, entropy, specific heat, etc. without reference to any entitary

* This example is taken from Stafleu where he discussed the way in which thermodynamics abstracts from the typical structure of physical entities (Stafleu, 1966:133 ff).

$-634-$ 
specification. In statistical physics this abstraction can no longer be maintained, since here one has to account for the relation between the physical micro-structures constituting macro-systems, and thermodynamics. This implies that the typical totality-character of physical entities should be recognized. Therefore, specific heat is dealt with differently in statistical physics according to the physical state of physical entities (compare the solid state with the gaseous state). In thermodynamics, however, the expression specific heat is used in a purely modal-functional sense, without any specification as regards the nature of a solid state, fluid state or gaseous state.

Instead of identifying the modal/typical distinction with that between universality and individuality, we should, therefore, use the distinction between (unspecified) universality and specified universality. The latter form of universality is restricted to a particular class of subjects whereas the former applies without any specification or qualification to all possible subjects. It is for this very reason that the former type of universality is an essential feature of the modal aspects - after all, every entity functions in principle in every modal aspect.

\section{SUITABLE CATEGORIES}

Dooyeweerd uses the term individuality-structure to indicate the applicability of a structural order for the existence of individual entities. Van Riessen prefers to call this law for entities identity-structures, since as such it guarantees the persistent identity of all entities (1970:158). Stoker speaks about "idionne" (1984:7 ff.), in order to indicate the 'own-stance' ('eiestandigheid' and not 'substance') of entities (cf. also Stoker 1967:240 ff.). My own preference is to use the notion of entitystructures, since every entity-structure guarantees both the individuality and the identity of every concrete entity. In a recent work, M. Verbrugge (1984) introduces his own distinct systematic account about the nature of (what he calls) functors, a word also used by Henk Hart for the dimension of entities (Hart, 1984:445-446). As a substitute for the notion of an individuality-structure, Verbrugge advances the term: idionomy (1984:81ff; 91ff). Of course this term may also cause misunderstanding if it is taken to mean that each individual creature $-635-$ 
(subject) has its own unique law. What is intended is that every type of law (nomos) is meant to delimit and determine unique subjects. In other words, however specified the universality of the law may be, it can never, in its bearing on unique individual creatures, itself become an (unique) individual. Another way of grasping the meaning of Dooyeweerd's notion of an individuality structure is, in following an oral suggestion by Roy Clouser (Zeist. August 1986), to call it a type-law This simply means that all entities of a certain type conform to this law. Perhaps, for the sake of clarity, we may recall the reference to the perspective given by M.D. Stafleu (1980:6, 11). Typical laws (typelaws, such as the Coulomb law - applicable only to charged entities and the Pauli principle - applicable only to fermions) are special laws which apply to a limited class of entities only, whereas modal laws hold universally for all possible entities.

7. NOMINALISM: THE UNDERLYING MOTIVE-POWER IN MODERN PHILOSOPHY

At this point we must mention the fact that the dual nature of nominalism forms the starting-point of two diverging philosophical developments in modern philosophy.

(a) On the one hand, it provided rationalism with the possibility to elevate human reason to the level of the creator of a rational order in reality. This follows from the fact that nominalism in fact transposes the universal side of entities into the human mind. But, as we have indicated, the universal side of entities is nothing but the manifestation of the conditionedness of entities by the relevant universal order for their existence. Consequently, if an entity is stripped of its orderliness (its universal side), it is simultaneously stripped of its being subjected to a universal creational order. What is left is factual reality in its unstructured, chaotic individuality and particularity (contingency). Driven by the new motive of

* From Grisebach the South African philosopher, Gerhard Rauche. -636- 
logical creation, this very feature of nominalism enabled modern philosophy from Descartes onwards to reconstruct all of reality in terms of natural scientific thought (characterized by Husserl as the rationalistic science-ideal) (cf. Husserl, 1954:119 ff). Only the extreme consequences of this natural science-ideal, cancelling in principle also human freedom, were questioned by Kant. Within the (limited) domain of the science-ideal, however, Kant drew the ultimate rationalistic conclusion of nominalism. The way in which he worked this out was strongly influenced by Galilei (cf. Holz, 1975:345-358). In relation to the natural scientific meaning of constancy and change, Galilei formulated a thought-experiment, and without taking account of any sense-experience, arrived at his law of intertia. Out of the spontaneous subjectivity of man's pure understanding he derived this law and prescribed it to moving entities. This prepresents the crucial epistemological turn in modern philosophy in ascribing the primacy no longer to the object, but to the subject. Kant drew the radical 'subjectivistic' conclusion: the laws of nature are a priori contained in the subjective understanding of man: "understanding creates its (a priori) laws not out of nature, but prescribes then to nature" (1783, par. 36, p. 320).

Indeed, Kant tried to consolidate and strengthen the preceding natural science-ideal, be it in the restricted form of the rationalistically elevated understanding which (though limited to sensibility in order to save a separate super-sensory domain for the practical-ethical freedom of autonomous man) is considered to be the a priori (formal) law-giver of nature! Nominalism created a vacuum by leaving factual reality in its individuality unstructured. In order to fill up the lack of determination thus created, Kant introduced human understanding to take hold of this vacant position. To be sure, Kant did not merely transpose the universal side of entities

inherited the following problem: "But can man exist at all without constituting himself? Can he exist in utter contingency?" (cf. Rauche, 1966:97). For both of them contingent experience simply represents that which is given to us in its unstructuredness. 
into human understanding, but in fact elevated human understanding to the level of the conditioning order for things.

(b) On the other hand, nominalism provided a starting-point for all those trends in modern philosophy which, in an irrationalistic fashion, wanted to take the unique and contingent character of (mostly designated as: historical) reality seriously. This avenue opened up by nominalism was followed up by a variety of historicistic designs in modern philosophy, for example from the forth phase of Fichte's thought up to pragmatism, existentialism and contemporary neo-Marxism. If reality is tripped both of its orderliness and of its being subjected to a conditioning universal creational order, it seems to be a 'self-evident historicist truth' that everything is ultimately historical and therefore taken up in the dynamic and contingent ever-changing flow of historical events.

\section{CONCLUSION}

Due to the fact that the modal aspects (universally) condition our theoretical reflection on the nature of created reality, it is not surprising that they co-condition the very way in which we have to account for the way in which we can reflect upon the nature of rational knowing in both its forms: conceptual knowledge and idea knowledge. 
BIBLIOGRAFIE

CASSIRER, E. 1969. Substanzbegriff unf Funktionsvegriff. Darmstadt : Wissenschaftliche Buchgesellschaft.

DE VLEESCHAUWER, H.J. 1952, Handleiding by die studie van die Logika en die Kennisleer. Pretoria : J.J. Moreau \& Kie.

DOOYEWEERD H. 1935. De Wijsbegeerte der Wetsidee. Vol. II. Amsterdam : H.J. Paris.

DOOYEWEERD, H. 1953. A new critique of theoretical thought. Vol. 1. Philadelphia: The Presbyterian and Reformed Publishing Company.

DOOYEWEERD, H. 1955. A new critique of theoretical thought. Vol. 11. Philadelphia : The Presbyterian and Reformed Publishing Company.

FOWLER, H. 1987. Law, refularity and order in nature. Issues, 4:4-13, Wellington, New Zealand; Association for Christian Scholarship.

HART, H. 1983. The articulation of belief - A link between rationality and commitment. Tydskrif vir Christelike Wetenskap, 1st and 2nd quarter.

HART, H. 1984. Understanding our world, an integral ontology. New York : University Press of America.

HOLZ, Fr. 1975. Die Bedeutung der methode Galileis für die Entwicklung der Transzendentalphilosophie Kants. Philosophia Naturalis, 15(3).

HUSSERL, E. 1956. Die Krisis der europäischen Wissenschaften und die Tranzendentalen Phänomenologie (1936). Husserliana. Vol. VI. The Hague: Martinus Nijhoff.

JANICK, P. 1975. Tragheitsgesetz und Inertialsystem, in: Frege und die moderne Grndlagenforschung. Ed. Chr. Thiel, Meisenheim am Glan 
: Forschungsunternehmen der Fritz Thysen Stiftung Arbeitskreis "Wissenschaftstheorie".

KANT, 1. 1781/1787. Kritik der reinen Vernunft, 1781 (1987/2)).

Hamburg : Felix Meiner Verlag (1956).

MAIER, A. 1949. Die Vorläufer Galileis im 14. Jahrhundert. Roma.

POPPER, K. 1945. The open society and its enemies. Vol. II. London : Routledge $\varepsilon$ Kegan paul.

RAUCHE, G.A. 1966. The problem of truth and reality in Grisenbach's thought. Pretoria : Van Schaik.

STAFLEU, M.D. 1966. Quantumfysica en Wijsbegeerte der Wetsidee. Philosophia Reformata : 126-156.

STAFLEU, M.D. 1980. Time and again, a systematic analysis of the foundations of Physics. Bloemfontein/Toronto : Wedge/VCHO.

STAFLEU, M.D. 1987. Theories at work, on the structure and functioning of theories in Science, in particular during the Copernican Revolution. London : University Press of America.

STOKER, H.G. 1964. Die kosmiese dimensie van gebeurtenisse. Philosophia Reformata: 1-67.

STOKER, H.G. 1967. Oorsprong en rigting. Vol. I. Cape Town : Nasionale Handelsdrukkery.

STRAUSS, D.F.M. 1982. The modal aspects as points of entry to our experience of and reflection on created rality. (In Blokhuis, P., et. al. red, Wetenschap, Wijsheid, Filosoferen, 'Festschrift' to Van Riessen Assen : Van Gorcum. p. 159-173.)

STRAUSS, D.F.M. 1982. The place and meaning of Kant's Critique of Pure Reason (1781) in the legacy of Western philosophy. South African journal of Philosophy, 4(1):131-146.

$-640-$ 
VAN RIESSEN, H. 1970. Wijsbegeerte, Kampen : J.H. Kok NV.

VERBRUGGE, M. 1984. Alive, an enquiry into the origin and meaning of life. Vallecito, California: Ross House Books.

VISAGIE. P.J. 1979. Enkele opmerkings oor die spanning: Rasionalisme - Irrasionalisme. Tydskrif vir Christelike Wetenskap: 246-253.

VISAGIE, P.J. 1980. Some Basic concepts concerning the idea of origin in Reformational Philosophy and Theology. Tydskrif vir Christelike Wetenskap: 1-13, ist $\varepsilon$ 2nd quarter.

VOLLENHOVEN, H. 1961. De Consequent Probleem-historische Methode. Philosophia Reformata: 1-34.

VOLLENHOVEN, H. 196i. Isagooge Philosophiae. Unpublished edition of the "Filosofisch Instituut" of the Free University.

ZIGTERMAN, K. 1981. Form, universal, and individual in Aristotle. Tydskrif vir Christelike Wetenskap: 18-53. 